\title{
Economix
}

http://economix.fr

Document de Travail Working Paper 2014-08

\section{On the Political Economy of Public Safety Investments}

Tim Friehe Eric Langlais

Université de Paris Ouest Nanterre La Défense (bâtiment G)

200, Avenue de la République 92001 NANTERRE CEDEX

Tél et Fax : 33.(0)1.40.97.59.07

UMR 7235 université

Paris Ouest

Nanterre La Défense 


\title{
On the Political Economy of Public Safety Investments
}

\author{
Tim Friehe* Eric Langlais ${ }^{\dagger}$ \\ 17th January 2014
}

\begin{abstract}
This paper explores the interaction of private precaution and public safety investments when the latter are determined in a political process. We distinguish the scenarios in which the median victim influences public safety from the one in which the injurer lobbies the public agent, and analyze both negligence and strict liability with a defense of contributory negligence. We establish that the levels of injurer and victim care are always socially optimal for the equilibrium level of public safety. However, the equilibrium level of public safety differs from its first-best level and drastically depends on both the specifics of the political process and the liability rule applied. This entails that the level of social costs is critically determined by the choice between liability rules for a given political process.
\end{abstract}

Keywords: liability law, care levels, public safety, political economy, median voter, firm lobbying

JEL-Classification: K 13, D 72

\footnotetext{
${ }^{*}$ University of Bonn, Center for Advanced Studies in Law and Economics, Adenauerallee 24-42, 53113 Bonn, Germany. CESifo, Munich, Germany. E-mail: tim.friehe@uni-bonn.de.

${ }^{\dagger}$ EconomiX UMR 7235 CNRS \& Paris Ouest Nanterre, 200 Avenue de la République, 92001 Nanterre cedex, France. Telephone : + 33 (0) 140975 914. Email: Eric.Langlais@u-paris10.fr. We are grateful for the helpful comments offered by Claude Fluet, Tim Reuter, and Avraham Tabbach on an earlier version of this paper.
} 


\section{Introduction}

\subsection{Motivation and main results}

The efficient management of expected harm requires the use and successful coordination of different precautionary inputs. Such inputs may be provided by private and public agents. For example, the expected harm resulting from driving on the highway will be a function of the care exerted by the drivers and the maintenance effort by the government agency responsible for highways. Similarly, the government may vary the number of zebra crossings in a residential area and thereby influence both the behavior of potential victims and injurers and the accident risk. In another domain of life, controlling the societal risk posed by contagious diseases may be addressed by private and public measures (the latter, for instance, comprising free vaccinations at schools).

When public agents are involved, it is interesting to explore how they arrive at decisions. Political economy arguments suggest that public agents are - like any other agent - seeking to maximize an objective function subject to constraints, where the latter are due to the applicable political process in the present context (e.g., Mueller 2003). If that is the case, small differences in the political process may cause drastic differences in policy outcomes despite similar underlying problems to be addressed by policy. The recent floods in Germany provide an example. In this context, the expected harm resulting from the danger of flooding is addressed by both private and public precautions. Furthermore, the public safety measures put in place differed drastically across locations along the affected rivers due to citizen opposition to walls and dams in some places, despite comparable susceptibility of towns?

This paper explores the interaction of private precautions and public safety investments when the latter are determined in a political process, whereas private parties choose precautions subject to a liability rule $2^{2}$ In our framework, not only injurer and victim care have an impact on the level of expected harm but also public safety measures do. In technical terms,

\footnotetext{
${ }^{1}$ Refer, for example, to 'German flood prevention still can't prevent floods' at www.dw.de/german-floodprevention-still-cant-prevent-floods/a-16876765.

${ }^{2}$ The present study isolates the political influence on the level of public safety investments. Future research may incorporate the selection of the liability rule into the political process.
} 
we augment the bilateral-care framework by a third kind of precautionary input, namely, public safety investment. With regard to the political process, our analysis distinguishes the scenarios in which the median victim influences public safety from the one in which the injurer lobbies the public agent to modify public safety to his benefit (along the lines of Grossman and Helpman 1994). Potential victims vary in their level of expected harm and, thus, may have different valuations for a given level of public safety investment. Our comprehensive approach regarding political processes seems sensible given that the relative importance of respective parties for the public agent will vary according to the source of the expected harm considered. For example, some kinds of expected harm are simply more salient to potential victims than others, such that salient issues may be explicitly taken up in the political agendas of candidates up for a vote whereas other issues are more open to a more or less silent influence by lobby groups. Regarding the applicable liability rule, we analyze incentives under negligence and under strict liability with a defense of contributory negligence.

We establish that the level of public safety investment in equilibrium is contingent on both the political process and the liability rule. Furthermore, whereas the privately optimal levels of injurer care and victim care are always equal to the socially optimal ones conditional on the level of public safety, the equilibrium level of social costs exceeds its first-best level due to the distortion in the level of public safety investment. This distortion results from the political economy considerations in a way that depends on the applicable liability rule. Stated succinctly, while both liability rules achieve that private parties select constrained socially optimal care levels, the level of social costs that results when implementing negligence will differ from the one when implementing strict liability with a defense of contributory negligence.

The central forces that drive the distortion of public safety investments include the lack of full marginal internalization by policy-setting parties and the resultant existence of strategic effects of changes in the level of public precautions for the level of private costs. For example, when strict liability with a defense of contributory negligence applies and the median victim is decisive, then public safety investment is determined with a focus on its influence on the 
due-care standard directed at victims. In this scenario, excessive public safety investment results when public precaution and victim care are strategic substitutes, that is, when more public safety investment lowers the costs of obeying the due-care standard for politically influential victims. Alternatively, when the same liability rule is applied while the public agent is lobbied by the injurer, then public safety investment is co-determined by the total effect on the injurer's costs, where the total effect comprises the direct repercussion of higher public safety and the strategic effect of higher public safety on the level of victim care. In this sense, the politically influential party seeks to redistribute some of the expected personal burden to the other party by means of its impact on the level of public safety. What matters to the politically influential party is influenced by whether or not it bears the accident costs. For example, as argued above, when victims influence the political process and strict liability with a defense of contributory negligence applies, the only concern is with changing the applicable standard of care (as the accident costs fall on the injurer).

Our paper contributes to the literature in the following ways. First, we show that even though both negligence and strict liability induce optimal behavior by the private parties for given public safety investments, they affect the public investment differently and thereby the level of social costs. In this way, we contribute to the large literature on the preferability of negligence versus strict liability 3 It is shown that this results because different liability rules create divergent public safety incentives for politically influential parties. This finding is a result of the fact that, in equilibrium, a given party will be incentivized by the due-care standard under one liability rule, while being the residual bearer under the other one. Third, we clearly delineate in which way the incentives are shaped by the applicable political process for determining public safety investment.

\subsection{Related literature}

The present paper is related to articles addressing political economy aspects in the area of law, contributions dealing with the relationship of liability and regulation, and papers that consider multilateral care. Before we delve into these domains, we refer to the contribution

\footnotetext{
${ }^{3}$ For a recent survey, see Schäfer and Müller-Langer (2009), for example.
} 
by Jeleva and Rossignol (2009). They study the case in which the public provides some risk reduction effort according to a probabilistic voting outcome. Our paper differs from theirs because we focus on the interaction of public safety with private precautions, where the latter are incentivized by liability rules.

It has been noted for quite some time that the design and the functioning of law may be very much affected by the political context. For example, Rubin (2005) discusses the ways in which the tort regime is shaped by the influence of different organized groups such as lawyers, doctors, and businesses. Epstein (1988) and Rubin and Bailey (1994) forward related analyses. Rubin et al. (2001) compare litigation and lobbying as two alternative avenues for changing the law in common law systems both of which are open to any organized group. Our interest - how is the performance of policy instruments influenced by specifics of the political process - has been treated in different streams of the literature. For example, in the area of environmental economics, van't Veld and Shogren (2012) analyze the combination of environmental federalism and environmental liability rules, such that regions choose between liability rules and their design without internalizing all repercussions of these decisions. Focussing on environmental taxes instead of environmental liability, Fredriksson et al. (2010) consider the potential distortions due to a majority bias, that is, the majority party's favoring home districts over other districts. Such majority bias may rationalize a departure from the otherwise optimal federal district-level taxation. Related concerns also take center stage in the present contribution; namely, the fact that the party with the critical influence on the policy-setting public agent, either the injurer or the median victim, does not take into account all marginal effects.

In our paper, the government shapes the interaction between injurer and victim by setting the level of public safety. This may be interpreted as a form of regulation since the government thereby influences pros and cons of alternative courses of action. Shavell (1984a, b) has analyzed the case in which liability is plagued by disappearing defendant and judgment proofness problems and safety regulations do not achieve first-best outcomes because of their applicability across the board (that is, without being tailored to the specifics of the case). These and subsequent contributions (such as Bhole and Wagner 2008, Kolstad et al. 1990, 
Rouillon 2008, Schmitz 2000) have often been principally concerned with providing an efficiency explanation for the widespread joint use of regulation and liability. In contrast, our paper takes the joint use for granted and seeks to explore the consequences of having public intervention determined by some political process for the efficiency of different liability rules.

In our contribution, there are three different precautionary inputs affecting expected harm, where public safety investments are determined in an earlier stage and in an observable fashion. The scenario in which different input-providing parties move in sequence and the question of whether or not liability rules are capable of inducing the first-best outcome in such a setting have been discussed in Endres (1992), Friehe (2007), Shavell (1983), Winter (1994), and Wittman (1981). In contrast to these papers, in our framework, the party moving fiÂnrst (the public agent) never bears expected harm. However, the political process effectively provides for an influence of either the injurer or the victim on the determination of public safety. Nevertheless, public safety only provides an indirect influence on the interaction between the injurer and the victim, for example, because there is no level of public safety that can free the politically influential party (i.e., the level of care that will be compared to due care is the one set after the public safety investment is determined). Private precautions are determined simultaneously. Such a bilateral-care framework is one of the mainstays of the economics of liability law since Brown (1973).

\subsection{The plan of the paper}

Section 2 describes our model and the characteristics of the socially optimal outcome (i.e., the one that results when the different levels of care are all determined by a benevolent planner). In the remainder of our paper, we are interested in the functioning of tort law in different political contexts. Accordingly, we analyze the incentives of private parties to take precautions that are produced by liability rules (negligence and strict liability with a defense of contributory negligence) in different political environments. In section 3, we consider

public safety investments and the functioning of liability rules when the level of public safety is determined by a simple majority rule, where the population of potential victims represents the electorate. In section 4, we analyze an alternative scenario in which the injurer lobbies 
the public decision-maker in order to align the level of public safety investments with his objectives. Again, the analysis distinguishes the scenario in which injurers and victims are subject to either negligence or strict liability with contributory negligence. Section 5 concludes.

\section{The model and the social optimum}

\section{$2.1 \quad$ Model}

Our model is populated by three kinds of risk-neutral parties: the injurer, a public agent and a population of victims. The injurer undertakes a socially desirable activity, which imposes expected harm. The injurer, victims, and the public agent all have measures at hand to influence the level of the expected harm. Injurer precaution is denoted by $x \geq 0$, victim care by $y \geq 0$, and public safety is represented by $z \geq 0$. The costs of care are simply $x, y$, and $z$, respectively. Victims differ in their level of exogenous income denoted $\theta$, where $\theta \in[\underline{\theta}, \bar{\theta}]$ is distributed according to the cumulative density function $F$. The expected harm of a victim with income $\theta$ is assumed to be proportional to income and given by $l(x, y, z) \theta$. This mirrors that the harm incurred in an accident is often some function of the material wealth of affected individuals, such as in cases in which harm afflicts the individual's property or health (via lost earnings). The function $l(x, y, z)$ is strictly decreasing at a diminishing rate in all of its arguments (i.e., $l_{j}<0$ and $l_{j j}>0 \forall j=x, y, z$ ) and strictly convex (the implications of this are detailed in our appendix). The initial impact of each kind of precaution on the level of $l$ is considerable, such that $\lim _{j \rightarrow 0} l_{j}=-\infty$ whereas $\lim _{j \rightarrow \infty} l_{j}=0$. This ensures interior solutions for our different kinds of precaution.

Regarding the interactions of the three different safety measures with respect to the level of expected harm, we can distinguish the possibilities of substitutes, complements, or no interaction. When two care measures are substitutes (complements), this connotes that an increase in one kind of care lowers (increases) the marginal productivity of the other kind of care in reducing the level of expected harm. Alternatively, the marginal productivity

\footnotetext{
${ }^{4}$ In our section on voting by potential victims, we will have a political competition between two public agents in mind.
} 
of a kind of care may be unaffected by other precautionary investments. The literature has convincingly established that all cases are relevant in real-world examples (see, e.g., the discussion in Friehe and Tabbach forthcoming). Such relationships will be important for our analysis. We consider all possible scenarios regarding the interaction of injurer and victim care and of private care and public safety investments (i.e., they may be substitutes or complements), but assume that the influence of more public investment is the same for both kinds of private precaution (i.e. $x$ and $y$ are both either substitutes or complements to $z)$ in order to have fewer case distinctions.

\subsection{Social optimum}

The benevolent policy maker chooses injurer care, victim precautions, and public safety investments to minimize the sum of expected harm and precaution expenditures. One level of both $x$ and $z$ applies to all victim types, that is, injurer and public precaution cannot be tailored to individual victims. This also implies that the precaution of the injurer and the government may be interpreted as durable as they are applicable to many potential interactions (see, e.g., Nussim and Tabbach 2009).

The first-best allocation that takes this realistic restriction into account follows from

$$
\min _{x, y(\theta), z} S C=x+\int_{\underline{\theta}}^{\bar{\theta}}[y(\theta)+l(x, y(\theta), z) \theta] d F(\theta)+z .
$$

Given the convexity of $l$, the first-order conditions are necessary and sufficient to characterize the unique socially optimal outcome defined by

$$
\begin{aligned}
1+\int_{\underline{\theta}}^{\bar{\theta}} l_{x}\left(x^{*}, y^{*}(\theta), z^{*}\right) \theta d F(\theta) & =0 \\
1+l_{y}\left(x^{*}, y^{*}(\theta), z^{*}\right) \theta & =0 \forall \theta \in[\underline{\theta}, \bar{\theta}] \\
1+\int_{\underline{\theta}}^{\bar{\theta}} l_{z}\left(x^{*}, y^{*}(\theta), z^{*}\right) \theta d F(\theta) & =0 .
\end{aligned}
$$

The system (2)-(4) is solved by $\left(x^{*}, y^{*}(\theta), z^{*}\right)$, where $\theta \in[\underline{\theta}, \bar{\theta}]$, which represent the efficient care levels for our three kinds of agents and yield minimal social cost $S C^{*}=S C\left(x^{*}, y^{*}(\theta), z^{*}\right)=$ $\min _{x, y(\theta), z} S C$. 
The marginal costs of care are equal to one for injurer care, victim precautions, and public safety investments. In contrast, the marginal benefits of care are contingent on whether it is the precaution taken by an injurer, victim, or the public agent. The marginal benefit of injurer care is the average marginal decrease in the expected harm of the whole population of victims. The marginal impact of more injurer care varies for different victim types. Socially optimal victim care is type-specific and increasing with income, as follows from (3). The condition for first-best public safety investment is similar to that for injurer care in that the same level applies to all victims. Again, the marginal impact of more public safety varies for different victim types.

Next, we analyze the decentralization of decision-making when private parties are subject to one of two liability rules, either negligence or strict liability with a defense of contributory negligence, focusing on the influence of the political process.

\section{Public safety investment influenced by potential vic- tims' vote}

In this section, we will consider the scenario in which the level of public safety investment is influenced by potential victims' vote. More specifically, we assume that the level of public safety investment follows from the preferences of the median voter in the population of potential victims $5^{5}$ In other terms, the public agent is no longer a benevolent planner but concerned only about receiving the majority of votes. In our application, the policy space comprises both the level of public safety investment and the level of the proportional income tax required for financing. However, the fact that the latter is a function of the former via the budget constraint makes the election a single-issue one. In this election, public agents announce their preferred combination of public safety and income tax and are bound by their announcement (i.e., there is full commitment).

Our analysis will distinguish the scenario in which injurers and victims are subject to

\footnotetext{
${ }^{5}$ This will be the political outcome when two public agents compete for a simple majority in a single-issue election when voters have single-peaked preferences and the distribution of voters is unimodal (e.g., Mueller 2003). We assume that these characteristics apply and will discuss the shape of victims' preferences explicitly below.
} 
negligence from the one in which they are subject to strict liability with contributory negligence ${ }^{6}$ The game comprises strategic interactions between the injurer and the victims, and between the private parties and the public agent. In contrast, there is no strategic interdependence among potential victims.7 This last fact follows from assuming that the victim's investment in safety influences only its personal expected harm and not that of other victims.

\subsection{When negligence applies}

Regarding the timing of decisions and the information available when negligence applies, we assume the following: In the first stage, the level of public safety investment is determined in the political process to be made clearer below. The due-care standard that is addressed at the injurer under negligence is denoted by $x_{s}$ and is assumed to be equal to the socially optimal injurer care level for the given level of public safety, that is, it follows from solving (2)-(3) for the given level of $z$. As a result, the selection of the public safety investment at stage 1 co-determines the due-care standard relevant at the second stage. Obeying this duecare standard relieves the injurer from the duty to compensate the victim for harm incurred. In stage 2, both private parties determine their precaution taking the level of due care and the level of public safety investment into account. We will solve the game by backward induction.

At the second stage, the injurer determines whether or not to choose the due-care level for the given level of public safety investment, facing the following private cost function:

$$
I C^{N}= \begin{cases}x+\int_{\underline{\theta}}^{\bar{\theta}} l(x, y(\theta), z) \theta d F(\theta) & \text { if } x<x_{s} \\ x & \text { if } x \geq x_{s}\end{cases}
$$

The first line is minimized by the socially optimal response to given care by the population of victims. The second line is minimized by $x_{s}$. By the same token, for the given level of public safety investment the victim with income $\theta$ chooses the care level that minimizes

$$
V C^{N}= \begin{cases}y & \text { if } x<x_{s} \\ y+l(x, y, z) \theta & \text { if } x \geq x_{s}\end{cases}
$$

\footnotetext{
${ }^{6}$ Note that we consider a framework in which both the injurer and the victim take care, implying that a strict liability rule without a defense of contributory negligence must induce inefficient choices with regard to private care (see, e.g., Shavell 2007).

${ }^{7}$ For an alternative framework, see Friehe (2012).
} 
It is cost-minimizing for the victim to choose no care when the injurer disobeys due care. By standard reasoning, the Nash equilibrium of the subgame represented by stage 2 is such that the injurer abides by the standard $x_{s}=x(z)$ (which satisfies the condition equivalent to (2) for any given $z$ ) and that the victim with income $\theta$ chooses a level of care $y(\theta, z)=$ $\arg \min _{y}[y+l(x, y, z) \theta]$ (which thus satisfies the condition equivalent to (3) for any given $z$ ). As a result, each party selects a care level that is socially optimal for the given level of public safety investment previously selected. This result is summarized in:

Lemma 1 Suppose that negligence applies and uses the efficient due-care standard for the given level of public safety investment (i.e., z). Then, the injurer and the victims choose efficient levels of injurer and victim precaution for any given level of public safety.

Before turning to the first stage, it is useful to study how the care levels selected by the private agents in stage $2, x(z)$ and $y(\theta, z)$, respond to changes in the level of public investment determined in stage 1 . The care levels elected at stage 2 (one of which is equal to the due-care standard) are by Lemma 1 the socially optimal levels described in (2) and (3), where the care choice of the injurer is guided by the court's adaptation of the due care standard. We must evaluate

$$
\begin{aligned}
& \left(\int_{\underline{\theta}}^{\bar{\theta}}\left[l_{x x}(x, y(\theta), z) \frac{d x(z)}{d z}+l_{x y}(x, y(\theta), z) \frac{\partial y(\theta, z)}{\partial z}+l_{x z}(x, y(\theta), z)\right] \theta d F\right) d z=0 \\
& \left(\left[l_{x y}(x, y(\theta), z) \frac{d x(z)}{d z}+l_{y y}(x, y(\theta), z) \frac{\partial y(\theta, z)}{\partial z}+l_{y z}(x, y(\theta), z)\right] \theta\right) d z=0 .
\end{aligned}
$$

The change in the level of injurer care in response to a variation in the level of public safety is not a function of $\theta$, because injurer care is determined in view of the whole population of victims. In contrast, the way in which victim care changes when public safety increases may be type-specific. This leads to

$$
\begin{aligned}
\frac{d x(z)}{d z} & =\frac{\int_{\underline{\theta}}^{\bar{\theta}} l_{y y}^{-1}\left[l_{x y} l_{y z}-l_{x z} l_{y y}\right] \theta d F}{\int_{\underline{\theta}}^{\bar{\theta}} l_{y y}^{-1}\left[l_{x x} l_{y y}-l_{x y}^{2}\right] \theta d F} \\
\frac{\partial y(\theta, z)}{\partial z} & =-l_{y y}^{-1}\left[l_{y z}+l_{x y} \frac{d x}{d z}\right] .
\end{aligned}
$$


Note that the denominator of $d x / d z$ is positive by the convexity of $l(x, y, z)$ (refer to our appendix for more detail). Thus, the influence of a change in public safety on the optimal level of injurer and victim care results from two effects that we now discuss, one of which is direct and the other one indirect.

The direct effect regarding injurer care results from the influence of higher public safety on the marginal productivity of injurer care in reducing expected harm (i.e., $l_{x z}$ ). The indirect effect regarding injurer care results from the influence of higher public safety on the marginal productivity of victim care (i.e., $l_{y z}$ ), and the repercussions of the implied change in the level of victim care for the marginal productivity of injurer care (i.e., $l_{x y}$ ). This makes clear that the comparative-statics results critically depend on the relationship between private care and public care, on the one hand, and on the one between injurer and victim care on the other. When injurer and victim care are complements (i.e., when $l_{x y}<0$ ), the direct and the indirect effect will go in the same direction. However, the two effects go in opposing directions when injurer and victim care are substitutes with respect to lowering expected harm (i.e., when $l_{x y}>0$ ). Overall, the statements in (9) and (10) may be used to arrive at the following lemma. The proof of this result and those to follow are relegated to our appendix.

Lemma 2 (1) Suppose $l_{x y} \leq 0$. Private care and public safety are strategic complements (substitutes) when $l_{j z}<(>) 0$ for $j=x, y$.

(2) Suppose $l_{x y}>0$. Private care and public safety are strategic complements (substitutes) when both $l_{j z}<(>) 0$ for $j=x, y$ and the direct effect of a change in $z$ dominates.

(3) Suppose $l_{x y}>0$. When the indirect effect of a change in $z$ dominates, injurer and public care are strategic substitutes (complements) when $l_{j z}<(>) 0$ for $j=x$,y, implying that victims and public care are strategic complements (substitutes).

The comparative-statics results of private care when public safety investments change depend only on how the productivity of private care is influenced by public care (i.e., $l_{j z}$ ) when the two kinds of private care are complements or independent of one another in their influence on the level of expected harm (i.e., $\left.l_{x y} \leq 0\right)$. As a result, we obtain both $d x(z) / d z>0$ 
and $\partial y(\theta, z) / \partial z>0$ when $l_{j z}<0$. A higher level of public safety investment increases the marginal productivity of own care, thereby calling for a higher investment. The implied change in the level of care of the other private party is inconsequential or supportive depending on whether $l_{x y}<0$ or $l_{x y}=0$. In contrast, when injurer and victim care are substitutes with respect to lowering $l$ (i.e., when $l_{x y}>0$ holds), we obtain that the direct effect and the indirect effect oppose one another. As a result, when the direct effect of a change in the level of public safety investment dominates, the sign of the change in private precaution is the same for both kinds of private care and depends on how public safety influences the marginal productivity of private care. When the indirect effect dominates, the changes in the levels of private care go in opposite directions.

At the first stage, the level of public safety investment is determined. We suppose that there is a political competition between two public agents who are bound by their announced policy platform. Our electorate - the population of potential victims - is heterogeneous only with regard to the parameter $\theta$. The level of minimized private costs of the median victim with income $\theta_{m}$ follows from

$$
\min _{z} V C^{N}\left(z, \theta_{m}\right)=y\left(z, \theta_{m}\right)+l\left(x(z), y\left(z, \theta_{m}\right), z\right) \theta_{m}+\tau \theta_{m}
$$

where $\tau$ represents the tax rate implied by the expenditure $z$, following from

$$
z=\tau \int_{\underline{\theta}}^{\bar{\theta}} \theta d F=\tau E .
$$

Substituting $\tau=z / E$ from (12), the privately optimal level of public safety investment for the median victim satisfies $\frac{\partial}{\partial z} V C^{N}\left(z, \theta_{m}\right)=0$ (assuming an interior solution and $\frac{\partial^{2}}{\partial z^{2}} V C^{N}\left(z, \theta_{m}\right)>$ $0)$, where

$$
\frac{\partial}{\partial z} V C^{N}\left(z, \theta_{m}\right)=[\underbrace{l_{x}\left(x(z), y\left(\theta_{m}, z\right), z\right) \frac{d x}{d z}}_{A}+\underbrace{l_{z}\left(x(z), y\left(\theta_{m}, z\right), z\right)}_{B}] \theta_{m}+\theta_{m} / E
$$

using the envelope theorem to simplify the expression. Term A represents that the victim considers that a change in public safety changes the level of care required from the injurer via the due-care standard. This is a strategic effect absent in the trade-off of the benevolent 
policy maker, implying a potential divergence between privately and socially optimal public safety. However, this strategic effect presents an argument for public safety investments only when public safety and injurer care are strategic complements (i.e., when $d x / d z>0$ ). Term B represents the direct effect from higher public safety on the median victim's expected harm level. The median victim's abstracting from the influence of public safety investment on other victims' expected harm presents another reason for a divergence between privately and socially optimal public safety. Depending upon the way in which the marginal productivity is influenced for different victim types, this may entail an under- or overestimation of the marginal benefits of public safety. Finally, the term $\theta_{m} / E$ represents the marginal cost of requiring more public safety to the median victim, relative to the marginal costs for the average potential victim. This ratio will be less than one when the median victim has less than average income. This would imply that the victim underestimates the marginal costs of public safety investment due to the fact that the bulk of tax payments is made by the better-off victims.

In order to explore in which way the preference for public safety investment depends on the level of income, we take the derivative of (13) divided by $\theta_{m}$ with respect to $\theta_{m}$ (thereby supposing an interior solution for $z$ )

$$
\frac{\partial^{2} V C^{N}}{\partial z \partial \theta_{m}}=[\underbrace{l_{x y}(x(z), y(z, \theta), z) \frac{d x}{d z}}_{A}+\underbrace{l_{y z}(x(z), y(z, \theta), z)}_{B}] \frac{\partial y}{\partial \theta_{m}}
$$

with $\frac{\partial y}{\partial \theta}>0$ (see condition (3)). The change of injurer care induced by a variation in public safety is not influenced by the identity of the victim we consider here (i.e., $d x / d z$ remains the same). The derivative in (14) may be used for the following lemma stated for interior solutions.

Lemma 3 (1) Suppose $l_{x y} \leq 0$. Victims with higher income desire more (less) public safety when $l_{j z}<(>) 0$ for $j=x, y$.

(2) Suppose both that $l_{x y}>0$ and that the direct effect of a change in $z$ dominates in determining $d x / d z$. Victims with higher income desire more (less) public safety when (i) 
$l_{y z}<0$ and $\left|l_{x y} \frac{d x}{d z}\right|<(>)\left|l_{y z}\right|$ and (ii) $l_{y z}>0$ and $\left|l_{x y} \frac{d x}{d z}\right|>(<)\left|l_{y z}\right|$.

(3) Suppose both that $l_{x y}>0$ and that the indirect effect of $z$ dominates in determining $d x / d z$. Victims with higher income desire more (less) public safety when $l_{j z}<(>) 0$ for $j=x, y$.

The result reported in Lemma 3 can be readily explained. Generally, a victim with a higher level of income will select a higher level of victim care in stage 2 because the individual exposure to the accident risk is higher. The implications of this regarding the preference for public safety depend on the relationships between the different kinds of care. Consider, for example, the scenario considered in (1). When public safety lowers the marginal productivity of private care (i.e., when $l_{y z}>0$ ), then a richer victim values the direct effect less (represented by a positive Term B). The fact that injurer care decreases with the public safety investment in this case is also less of a concern for a victim with higher income (represented by a positive Term A). In other terms, both sources of marginal benefit from higher public safety are less important for richer potential victims, because they rely to a greater extent on own precaution.

The median-voter theorem may be applied under the assumption that voters have singlepeaked preferences on the one-dimensional policy space and follow a unimodal distribution. As argued before, the policy space is in our framework given by the different levels of public safety investment. Single-peakedness results when (14) changes its sign at most once.

We summarize our analysis of behavior under negligence as follows:

Proposition 1 Suppose that negligence applies. The level of public safety that is optimal for the median victim may exceed or fall below the socially optimal level since: (1) The median victim underestimates the marginal costs of public safety when $\theta_{m} / E<1$, and overestimates them when $\theta_{m} / E>1$. (2) The median victim strategically incorporates the influence on the due-care standard, a strategic effect that induces more (less) public safety when $l_{x y} \frac{\partial x}{\partial z}<(>) 0$. (3) The marginal effect of public safety is taken into account only for the median victim, instead of for the population of victims. 
The level of public safety that minimizes the expected costs of the median voter is generally different from the level that minimizes social costs. Whereas this basic result will reemerge in the next section that concerns strict liability with a defense of contributory negligence, the reason for the divergence between private and social marginal effects will be fundamentally different.

\subsection{When strict liability with a defense of contributory negligence applies}

The sequence of events remains unchanged; the only difference is that private parties are subject to strict liability with a defense of contributory negligence when determining precaution at stage 2 . This liability rule addresses a due-care standard denoted $y_{s}(\theta)$ at each victim. 8 This due-care standard is the socially optimal victim care level given the level of public safety, that is, it follows from solving (2) and (3). In other terms, the determination of public safety investment at stage 1 will have repercussions on the due-care standard addressed at potential victims in stage 2. Obeying the due-care standard ensures that the victim receives compensation in the event of an accident.

At the second stage, the victim with income $\theta$ chooses the care level that minimizes second-stage costs $\forall \theta \in[\underline{\theta}, \bar{\theta}]$

$$
V C^{S L C N}= \begin{cases}y & \text { if } y \geq y_{s}(\theta) \\ y+l(x, y, z) \theta & \text { if } y<y_{s}(\theta)\end{cases}
$$

The first line is minimized by due care. The second one by the socially optimal response to given care by the injurer and the public agent. The injurer determines care for given public safety and conjectured victim care, facing the following cost function: ${ }^{9}$

$$
I C^{S L C N}= \begin{cases}x+\int_{\underline{\theta}}^{\bar{\theta}} l(x, y(\theta), z) \theta d F(\theta) & \text { if } y \geq y_{s}(\theta) \forall \theta \in[\underline{\theta}, \bar{\theta}] \\ x & \text { if } y<y_{s}(\theta) \forall \theta \in[\underline{\theta}, \bar{\theta}]\end{cases}
$$

\footnotetext{
${ }^{8}$ We focus the case in which the court can observe victim type and can thus condition the due-care standard on this observation. Otherwise the negligence rule would be preferable as it places the due-care standard at the party without heterogeneity.

${ }^{9}$ We state (16) anticipating symmetric victim behavior regarding compliance and non-compliance with due care.
} 
The first line is minimized by the socially optimal response to given care by the victim and the public agent. The second line is minimized by zero. Once again, standard reasoning yields the observation that private parties will choose socially optimal levels of care.

Lemma 4 Suppose that strict liability with a defense of contributory negligence applies and uses the efficient due-care standard for the given level of $z$. Then, the injurer and the victims choose efficient levels of injurer and victim precaution for any given level of public safety.

It follows from Lemma 4 that the results regarding how private care responds to a change in the level of public safety derived for the case of negligence, that is, (9) and (10), are similarly applicable in the present context. As a result, we can utilize the findings described in Lemma 2 for our subsequent analysis.

At the first stage, there is again political competition between two agents vying for public office. The population of voters is constituted by victims and the issue at stake is the level of public safety investment financed by proportional income taxes. The difference to the analysis considered before lies in the level of minimized private costs of a victim with income $\theta_{m}$ which follows from

$$
\min _{z} V C^{S L C N}\left(z, \theta_{m}\right)=y\left(\theta_{m}, z\right)+\tau \theta_{m}
$$

in the case of strict liability with a defense of contributory negligence, subject to the budget constraint (12). The major difference in the objective function of the potential victim with income $\theta_{m}$ comes from the victim's anticipation of being fully compensated for any harm incurred in stage 2. This removes expected harm from the objective function of the victim when it comes to determining the level of public safety investments in stage 1 . The privately optimal level of public safety for a victim with income $\theta_{m}$ thus follows from

$$
\frac{\partial}{\partial z} V C^{S L C N}\left(z, \theta_{m}\right)=\frac{\partial y\left(\theta_{m}, z\right)}{\partial z}+\frac{\theta_{m}}{E}
$$

using again that $\tau=z / E$ due to 12 . This shows that the single source of marginal benefit lies in the influence on the due-care standard directed at the victim in stage 2 . When an increase in public safety increases socially optimal victim precaution in stage 2 (i.e., when $\partial y / \partial z>0)$, all victim types share the opinion that public safety should not be used since 
this would only increase private $\operatorname{costs}\left(\frac{\partial}{\partial z} V C^{S L C N}(z, \theta)>0\right)$. According to Lemma 2 , this always results when $l_{x z}<0$ and either injurer and victim care are complements or they are substitutes and the marginal effect is driven by the direct effect. In the alternative scenario in which $\partial y / \partial z<0$, it becomes of interest whether potential victims can be arranged according to their interests in public safety in a way amenable to the median-voter theorem, where the condition for the interior level of public safety can be rearranged to $-\frac{\partial y\left(z, \theta_{m}\right)}{\partial z}=\frac{\theta_{m}}{E}$. Note that the marginal costs of victims with a higher income are necessarily greater in this regime. With respect to the marginal benefit, the effect is unclear. Specifically, when the due-care standard directed at potential victims with higher income levels reacts less strongly to a change in public safety than that of potential victims with low income, we obtain that the marginal benefits of public safety are lower for richer individuals. In contrast, when the due-care standard directed at potential victims with higher income levels reacts more strongly to a change in public safety than that of potential victims with low income, then it is central whether or not marginal benefits outpace the increase in marginal costs.

Starting from (10), we obtain

$$
\frac{\partial^{2} y}{\partial z \partial \theta}=-\frac{\partial y}{\partial \theta} l_{y y}^{-2}\left[\left(l_{y y z}+l_{x y y} \frac{d x}{d z}\right) l_{y y}-l_{y y y}\left(l_{y z}+l_{x y} \frac{d x}{d z}\right)\right] .
$$

This may be used to arrive at the following result.

Lemma 5 Suppose that strict liability with a defense of contributory negligence applies and that third derivatives are negligible in magnitude. Then, victims with higher income desire (weakly) less public safety.

The incentives for public safety are drastically different under strict liability with a defense of contributory negligence when compared to the case of negligence studied in the previous section. Under negligence, it was a possible outcome that potential victims with a higher level of income desire a higher level of public safety investments. This is ruled out under present circumstances. The fundamental reason lies in victims' being fully compensated by the injurer in the event of an accident, which makes potential victims ignore repercussions of public safety on the level of expected harm. With regard to the level of public safety 
investment determined in stage 1, we thus obtain the following result (relying principally on (18)).

Proposition 2 Suppose that strict liability with a defense of contributory negligence applies. The level of public safety that is optimal for the median victim will be (i) equal to zero when

$\partial y / \partial z>0$, (ii) may be positive when $\partial y / \partial z<0$, where obtaining a positive level of public safety becomes more likely when the median victim becomes poorer.

In the present context, victims with a higher level of income perceive a higher marginal cost, whereas the marginal benefit is likely to be relatively unchanged for different income levels. As a result, it is more likely that the given marginal benefit will suffice to make an interior public safety level privately optimal for the median victim when the income level of the median victim is relatively low.

\section{Public safety is influenced by the injurer lobbying the public agent}

Potential injurers seek to influence regulatory outcomes to their advantage in many areas. For example, the empirical analysis by Fredriksson and Wollscheid (2008) is consistent with a model in which firms pay contributions to the policy maker in order to lower the demands regarding pollution abatement. This basic idea will also be our concern in this section. The injurer can lobby the public agent in office who cares about both political contributions and welfare. Following the approach by Grossman and Helpman (1994), we assume that lobbying can be represented by a monetary transfer $S$ from the injurer to the public official when the latter implements the level of public care $z$. Given the wide array of uses for political donations, such as funding election campaigns, retiring debt from previous elections, and deterring rivals, it is reasonable to assume that donations indeed influence government decisions (Damania 2001).

The timing of events in our analysis is as follows: In the first stage, the injurer first proposes a menu $S(z)$ to the public agent, who then chooses a level of public safety $z$. We 
continue to assume that resources needed for public safety investment will be raised via taxes from the population of victims (as we imagine the injurer to be a firm). In stage 2 , the injurer and the potential victims determine their private precaution taking the level of public safety investment and the due-care standard into account, where the due care-standard will be directed either at the firm or the victim depending on the liability rule they face. Again, the analysis distinguishes the scenario in which injurers and victims are subject to negligence from the one in which they are subject to strict liability with contributory negligence. We will address the former case first.

\subsection{When negligence applies}

Solving the game backwards, we first analyze the stage in which injurer and victim determine their levels of care simultaneously, for a given level of public safety investment. Under negligence, the due-care standard is directed at the injurer. It is straightforward to verify that the subgame corresponding to stage 2 has the same equilibrium as the one detailed in section 3.1, that is, the injurer and the victims choose the first-best levels of care for the given $z$. This connotes that the injurer anticipates taking due care and being freed from the obligation to compensate harmed victims in stage 2 when influencing political decisionmakers in stage 1 . In this outcome, the injurer bears only the costs of taking the standard of care. This allows us to turn directly to the analysis of the first stage.

In stage 1, the injurer offers some level of political contributions $S$ for each level of public safety $z$ to the public agent. The contribution $S$ offered by the injurer should minimize private costs

$$
I C^{N}=x(z)+S
$$

The public agent cares about social costs and political contributions, such that the public safety $z$ should minimize

$$
G(z)=\alpha S C-S
$$

where $\alpha$ is the weight attached to social costs relative to political contributions. Both injurer and public agent take into account the levels of injurer and victim care that result in stage 
2, $x(z)$ and $y(\theta, z)$, as a function of the level of public safety investment.

The equilibrium consists of a political contributions schedule $S(z)$ and a level of public safety investment $z$ such that: (i) the contribution schedule $S(z)$ is feasible, and (ii) the level of public safety investment $z$ minimizes the objective function $G(z)$ of the public agent for the given $S(z)$. Relying on Lemma 2 of Bernheim and Whinston (1986), the necessary conditions for a subgame perfect Nash equilibrium regarding the political contribution and the level of public safety investment $(\hat{S}, \hat{z})$ are

$$
\begin{aligned}
& \hat{z} \in \arg \min \{G(z)\} \\
& \hat{z} \in \arg \min \left\{I C^{N}(z)+G(z)\right\}
\end{aligned}
$$

Condition (22) ensures that the resultant level of public safety minimizes the public agent's objective function given the contribution schedule $S(z)$. Condition (23) requires that it also minimizes the joint payoff of the firm and the public agent. The explanation for the inclusion of this condition is that should (23) not hold, then the injurer will have an incentive to change the strategy in order to incentivize the public agent to modify the public investment in safety as it allows for a capture of social surplus. It is easy to see that (22) and (23) entail that the equilibrium level $\hat{z}$ satisfies

$$
\begin{aligned}
& \alpha\left[1+\int_{\underline{\theta}}^{\bar{\theta}} l_{z}(x, y(\theta), \hat{z}) \theta d F\right]-\frac{\partial S}{\partial z}=0 \\
& \alpha\left[1+\int_{\underline{\theta}}^{\bar{\theta}} l_{z}(x, y(\theta), \hat{z}) \theta d F\right]+\frac{d x}{d z}=0
\end{aligned}
$$

by making extensive use of the envelope theorem, relying on the fact that $x$ and $y$ are socially optimal for the given level of public safety. Condition (24) shows that the slope of the contribution schedule is equal to the (weighted) marginal influence of a change in $z$ on social costs. Using that $\operatorname{sign} \frac{\partial S}{\partial z}=\operatorname{sign}\left[1+\int_{\underline{\theta}}^{\bar{\theta}} l_{z}(x, y(\theta), \hat{z}) \theta d F\right]$, we argue that the contribution schedule must be downward (upward) sloping at equilibrium public safety, when public safety entails a marginal benefit (cost) for society represented by $1+\int_{\underline{\theta}}^{\bar{\theta}} l_{z}(x, y(\theta), \hat{z}) \theta d F<(>) 0$. In combination with condition (25), the forces driving the absolute level of contributions in the political equilibrium with lobbying are easy to understand. When $d x / d z<0$, then 
the injurer desires that the public agent implements a level of public safety in excess of the efficient level, such that $1+\int_{\underline{\theta}}^{\bar{\theta}} l_{z}(x, y(\theta), z) \theta d F>0$. This requires that the public agent who cares about social costs according to $\alpha$ must be compensated for the distortion, such that $\partial S / \partial z>0$. Using 24 and 25 , we obtain

$$
\frac{\partial S}{\partial z}=-\frac{d x}{d z}
$$

The firm pays contributions to the policy maker in order to induce higher (lower) public safety investments when $d x / d z<(>) 0$. When a higher level of public safety increases the level of due care directed at the injurer, the public agent forfeits political contributions when increasing public safety investment (i.e., $\partial S / \partial z<0$ ). In the terminology of Bernheim and Whinston (1986), the political contribution schedule is locally truthful because the change in the political contribution is equal to the effect of the change in public safety on the firm's costs. In absolute levels, this entails $S(\hat{z})=\alpha\left(S C^{*}-S C(\hat{z})\right)$ (see also, e.g., Grossman and Helpman 1994). Hence, the political contribution level reflects the additional burden of social cost that injurers impose on society. Our main results follow from the condition determining public safety, (26), and are summarized in the next proposition.

Proposition 3 Suppose that negligence applies. The level of public safety that results in a political equilibrium with lobbying by the injurer will be below its efficient level when $d x / d z>$ 0. The public safety level implemented will be above its efficient level when $d x / d z<0$.

Under the negligence rule that uses a first-best due-care standard, injurers obey the standard of care and ignore expected harm. As a result, benefits from public safety from the injurer's standpoint may only arise when it lowers care costs in stage 2 . This would arise when a higher level of public safety makes a lower level of injurer care socially optimal, due to public and private care being strategic substitutes in reducing the level of expected harm. This parallels the argumentation for strict liability with a defense of contributory negligence in the scenario in which potential victims shape public policy by voting. 


\subsection{When strict liability with a defense of contributory negligence applies}

Under strict liability with a defense of contributory negligence, the victim determines whether or not to obey the due care standard that is set at the efficient level. As a result, the outcome of the interaction between the injurer and the victim in stage 2 is efficient care levels that solve (2) and (3) for given $z$. This entails that the injurer will have the sum of both costs of care and expected harm as individual costs in stage 2 .

In stage 1, the injurer offers political contributions $S$ to the public agent in order to minimize private costs,

$$
\min _{S} I C^{S L C N}=x(z)+\int_{\underline{\theta}}^{\bar{\theta}} l(x, y(\theta), z) \theta d F+S .
$$

The objective function of the public agent is still described by (21). Following the same argumentation detailed in section 4.1, the political contribution and the level of public safety $(\tilde{S}, \tilde{z})$ must be

$$
\begin{aligned}
& \tilde{z} \in \arg \min \{G(z)\} \\
& \tilde{z} \in \arg \min \left\{I C^{S L C N}(z)+G(z)\right\},
\end{aligned}
$$

where the equilibrium level of $\tilde{z}$ satisfies

$$
\begin{aligned}
& \alpha\left[1+\int_{\underline{\theta}}^{\bar{\theta}} l_{z}(x, y(\theta), \tilde{z}) \theta d F\right]-\frac{\partial S}{\partial z}=0 \\
& \alpha\left[1+\int_{\underline{\theta}}^{\bar{\theta}} l_{z}(x, y(\theta), \tilde{z}) \theta d F\right]+\int_{\underline{\theta}}^{\bar{\theta}}\left[l_{y}(x, y(\theta), \tilde{z}) \frac{\partial y}{\partial z}+l_{z}(x, y(\theta), \tilde{z})\right] \theta d F=0
\end{aligned}
$$

Condition (30) is similar to condition (24). Condition (31) differs from (25) in the strategic

effect of a change in public safety for the level of injurer costs. The influence of public safety on the level of victim care, $\partial y / \partial z$, may be positive or negative (see Lemma 2). Combining (30) and (31), we obtain

$$
\frac{\partial S}{\partial z}=-\int_{\underline{\theta}}^{\bar{\theta}}\left[\frac{\partial y}{\partial z} l_{y}(x, y(\theta), \tilde{z})+l_{z}(x, y(\theta), \tilde{z})\right] \theta d F
$$


As above, the political contribution schedule is locally truthful because the change in the political contribution is equal to the effect of the change in public safety on the firm's costs. However, the central difference is given by the fact that the injurer anticipates having to compensate expected harm. This leads the injurer to take into account the strategic effect of public safety on victims precaution, i.e., to value increases in public safety when it influences victim care in a way that lowers expected harm. Moreover, the direct influence of public safety regarding the level of expected harm is of importance. Our main results follow from the condition determining public safety, (32), and are summarized in the next proposition.

Proposition 4 Suppose that strict liability with a defense of contributory negligence applies. The level of public safety determined in a political equilibrium with lobbying by the injurer will be higher or lower than its efficient level since: (1) The injurer values the strategic influence of public safety on the due care standard directed at the victim when $\partial y / \partial z>0$. (2) The injurer values the direct marginal effect of public safety, while externalizing the marginal costs of it.

Under strict liability with a defense of contributory negligence with a due-care standard set at the efficient level, victims obey the standard of care and thereby shift expected harm to injurers. As a result, benefits from public safety from the firm's standpoint may arise via its influence on the level of expected harm and its impact on victim care-taking. Given that the injurer's objective function lacks the costs of public safety and victim precaution, the firm's influence on the public agent introduces a distortion away from the first-best outcome.

\section{Conclusion}

Liability rules are an important instrument to induce care-taking by private parties. Under standard assumptions, both negligence and strict liability with a defense of contributory negligence are capable of inducing socially optimal levels of private precaution and the first-

best level of social costs. However, in many (if not in most) circumstances, the level of expected harm is also influenced by regulation set by public agents. This paper shows that 
liability rules induce very different equilibria (implying very different levels of social costs), when the public agent chooses the regulation either to satisfy the needs of the median voter or to accommodate the preferences of the lobbying injurer. Even though the liability rules are still comparable in that the private precautionary investments will be socially optimal given the regulatory background, this equivalence by no means transfers to the endogenous level of regulation or the level of social costs in equilibrium. When it is realistic to assume that the regulatory background against which liability rules operate is indeed influenced by political economy aspects, then the decision for one liability rule over the other should also be based on the incentives of respective parties to influence policy makers. This follows from the fact that some parties will have an interest in regulation that is more closely aligned with that of society.

This study presents a first in-depth exploration of political economy issues in the realm of the economic analysis of liability law. For this, the paper has used standard assumptions such as full compensation of victims and due-care standards being set at the efficient level of care and enforced without legal error. Departures from such assumptions would influences the two liability rules considered in different ways. Moreover, it may be argued that such aspects of the application of liability law may also be described as being subject to related political economy influences as the level of regulation considered here. Such considerations are left for future research.

\section{References}

Bernheim, D., and Whinston, M. (1986). Menu auctions, resource allocation, and economic influence. Quarterly Journal of Economics, 60: 1-32.

Bhole B. and Wagner J. (2008), The joint use of regulation and strict liability with multidimensional care and uncertain conviction, International Review of Law and Economics, 28: 123-132.

Brown, J.P. (1973). Toward an Economic Theory of Liability. Journal of Legal Studies, 2: 323-349. 
Burrows P. (1999), Combining regulation and legal liability for the control of external costs, International Review of Law and Economics, 19: 227-244.

Damania, R. (2001), When the Weak Win: The Role of Investment in Environmental Lobbying, Journal of Environmental Economics and Management, 42: 1-22.

Dharmapala D. and Hoffmann S. (2005), Bilateral accident with intrinsically interdependent costs of precaution, Journal of Legal Studies, 34: 239-272.

Endres A. (1992), Strategic behavior under tort law, International Review of Law and Economics, 12: 377-380.

Endres A. and Bertram R. (2006), The development of care technology under liability law, International Review of Law and Economics, 26: 503-518.

Fredriksson, P.G., and Wollscheid, J.R. (2008). The political economy of investment: The case of pollution control technology. European Journal of Political Economy, 24: 53-72.

Fredriksson, P.G., Matschke, X., and J. Minier, 2010. Environmental Policy in Majoritarian Systems. Journal of Environmental Economics and Management, 59: 177-191.

Friehe T. (2007), On the similarity of bilateral harm an unilateral harm with role-type uncertainty, Review of Law and Economics, 3: 553-580.

Friehe T. (2008), On judgment proofness in the case of bilateral harm, European Journal of Law and Economics, 26: 175-185.

Friehe T. (2009), Sequential torts and bilateral harm, International Review of Law and Economics, 29: 161-168.

Friehe, T. (2012). Victim Interdependence in the Accident Setting. European Journal of Law and Economics, 33: 371-391.

Friehe, T., and Tabbach, A. (forthcoming). Judgment Proofness and the Choice Between Monetary and Non-monetary Care. Journal of Institutional and Theoretical Economics.

Grossman, G., and E. Helpman (1994), Protection for Sale, American Economic Review, 84: 833-850.

Hiriart Y., Martimort D. and Pouyet J. (2004), On the optimal use of ex ante regulation and ex post liability, Economics Letters, 84, 231-235.

Innes R. (2004), Enforcement costs, optimal sanctions, and the choice between ex-post liab- 
ility and ex-ante regulation, International Review of Law and Economics, 24, 29-48.

Jeleva M. and Rossignol S. (2009), Political decision of risk reduction: the role of trust, Public Choice, 139, p. 83-104.

Kim J. and Feldman A. (2006), Victim or injurer, small car or SUV: tort liability rules under role-type uncertainty, International Review of Law and Economics, 26: 455-477.

Kolstad C., Ulen T. and Johnson G. (1990), Ex post Liability form Harm vs. Ex ante Safety Regulation : Substitutes or Complements ?, American Economic Review, 80: 888-901.

Leong A. (1989), Liability rules when injurers as well as victims suffer losses, International Review of Law and Economics, 9, 105-111.

Mueller, D., 2003. Public Choice III. Cambridge: Cambridge University Press.

Nussim, J., and Tabbach, A.D. (2009), A revised model of unilateral accidents, International Review of Law and Economics, 29, 169-177.

Rouillon S. (2008), Safety regulation vs. liability with heterogeneous probabilities of suit, International Review of Law and Economics, 28: 133-139.

Rubin, P.H. (2005), Public choice and tort reform, Public Choice, 124: 223-236.

Rubin, P.H., Curran, C., and J.F. Curran (2001), Litigation versus legislation: Forum shopping by rent seekers, Public Choice, 107: 295-310.0

Schäfer, H.B., and F. Müller-Langer, 2009. Strict Liability versus Negligence. In: Faure, M. (Ed.), Tort Law and Economics. Cheltenham: Edward Elgar.

Schmitz P. (2000), On the joint use of liability and safety regulation, International Review of Law and Economics, 20: 371-382.

Shavell S. (1983), Torts in which victim and injurer act sequentially, Journal of Law and Economics, 26: 569-612.

Shavell S. (1984a), A model of the optimal use of liability and safety regulation, Rand Journal of Economics, 15, 271-280.

Shavell S. (1984b), Liability for harm versus regulation for safety, Journal of Legal Studies, 13, 357-374.

Shavell S. (1986), The judgment proof problem, International Review of Law and Economics, 12, 171-184. 
Shavell, S. (2007), Liability for Accidents. In: Polinsky, A.M., and S. Shavell (Eds.), Handbook of Law and Economics 1, Amsterdam: Elsevier, 139-182.

Van 't Veld K. and Shogren J.F. (2012), Environmental federalism and environmental liability, Journal of Environmental Economics and Management, 63: 105-119.

Winter H. (1994), Sequential torts with imperfect information, International Review of Law and Economics, 14: 35-40.

Wittman, D. (1994). Optimal Pricing of Sequential Inputs: Last Clear Chance, Mitigation of Damages, and Related Doctrines of Law. Journal of Legal Studies, 10: 65-91.

\section{Appendix}

\section{Convexity of expected harm}

By convexity, the next set of conditions is satisfied:

$$
\begin{aligned}
& l_{y y}>0 \\
& \left|\begin{array}{ll}
l_{x x} & l_{x y} \\
l_{x y} & l_{y y}
\end{array}\right|>0 \\
& l_{x z}\left|\begin{array}{cc}
l_{x y} & l_{y y} \\
l_{x z} & l_{y z}
\end{array}\right|-l_{y z}\left|\begin{array}{cc}
l_{x x} & l_{x y} \\
l_{x z} & l_{y z}
\end{array}\right|+l_{z z}\left|\begin{array}{cc}
l_{x x} & l_{x y} \\
l_{x y} & l_{y y}
\end{array}\right|>0
\end{aligned}
$$

The second line also writes as $l_{x x} l_{y y}-l_{x y}^{2}>0$.

\section{Proof of Lemma 2}

Claim (1) follows straightforwardly from (9) and (10). Claim (2) follows from the fact that $\operatorname{sign} \frac{d x}{d z}=\operatorname{sign} \frac{\partial y}{\partial z}=\operatorname{sign}\left(-l_{y z}\right)$ when the direct effect of a change in $z$ dominates in (9) and (10). Regarding claim (3), note that when the indirect effect of a change in $z$ dominates, then $\operatorname{sign} \frac{d x}{d z}=\operatorname{sign}\left(l_{x y} l_{y z}\right)$ and $\operatorname{sign} \frac{\partial y}{\partial z}=\operatorname{sign}\left(-\frac{d x}{d z} l_{x y}\right)$. As a result, we have $\frac{d x}{d z}>0$ when $l_{x y}>0$ and $l_{y z}>0$, whereas $\frac{d y}{d z}<0$ under these conditions, and vice versa. 


\section{Proof of Lemma 3}

We rely on the results established in Lemma 2 in the following. When $l_{x y} \leq 0$, the first term in the brackets in (14) is either equal to zero or of the same sign as the second term. When (14) is positive, this indicates that a marginal increase in public safety investment is increasing private costs for the considered victim type, such that this creates a demand for less investment. This establishes claim (1). When both $l_{x y}>0$ and the direct effect dominates in determining $d x / d z$, the first term in the brackets in (14) is always of the opposite sign when compared to the sign of the second term. As a result, results require a ranking of influences as done explicitly in claim (2). Next, we turn to claim (3). When both $l_{x y}>0$ and the indirect effect of $z$ dominates, we have $\operatorname{sign} \frac{d x}{d z}=\operatorname{sign}\left(l_{y z}\right)$. Thus, when

$l_{x y}>0$, the first term in the brackets in (14) is either equal to zero or of the same sign as the second term $l_{y z}$. When both $l_{x y}>0$ and the indirect effect dominates in determining $d x / d z$, the first term and thus the sum in the bracket has also the same sign as the second term $l_{y z}$.

\section{Proof of Lemma 4}

For a given level of public safety investment, the Nash equilibrium in the second stage is such that each party selects a care level that is socially optimal for the given level of public safety. Each victim $\theta$ chooses to obey the due-care standard $y_{s}(\theta)=y(\theta, z)$ which satisfies (4) for given $z$. At the same time, the injurer chooses $x(z)=\arg \min _{x}\left[x+\int_{\underline{\theta}}^{\bar{\theta}} l(x, y(\theta), z) \theta d F(\theta)\right]$ which satisfies the condition equivalent to (2) for given $z$.

\section{Proof of Lemma 5}

Let us consider condition (18) and evaluate:

$$
\frac{\partial^{2} V C^{S L C N}}{\partial z \partial \theta_{m}}=\frac{\partial^{2} y\left(z, \theta_{m}\right)}{\partial z \partial \theta_{m}}+\frac{1}{E}
$$

Under the assumption that third derivatives are negligible in magnitude, we find that the marginal benefit of public safety is not critically influenced by the income level of the victim. In contrast, the level of marginal costs are increasing with the income level of the victim. 
The qualification weakly ensures that the lemma also covers the case in which $\partial y / \partial z>0$, such that all victims prefer no public safety. 